\title{
A Treatment-Oriented Typology of Self-Identified Hypersexuality Referrals
}

\author{
James M. Cantor · Carolin Klein · Amy Lykins · Jordan E. Rullo • \\ Lea Thaler $\cdot$ Bobbi R. Walling
}

Received: 11 June 2012 / Revised: 29 December 2012 / Accepted: 29 December 2012 / Published online: 2 March 2013

(C) Springer Science+Business Media New York 2013

\begin{abstract}
Men and women have been seeking professional assistance to help control hypersexual urges and behaviors since the nineteenth century. Despite that the literature emphasizes that cases of hypersexuality are highly diverse with regard to clinical presentation and comorbid features, the major models for understanding and treating hypersexuality employ a "one size fits all" approach. That is, rather than identify which problematic behaviors might respond best to which interventions, existing approaches presume or assert without evidence that all cases of hypersexuality (however termed or defined) represent the same underlying problem and merit the same approach to intervention. The present article instead provides a typology of hypersexuality referrals that links individual clinical profiles or symptom clusters to individual treatment suggestions. Case vignettes are provided to illustrate the most common profiles of hypersexuality referral that presented to a large, hospital-based sexual behaviors clinic, including: (1) Paraphilic Hypersexuality, (2) Avoidant Masturbation, (3) Chronic Adultery, (4) Sexual Guilt, (5) the Designated Patient, and (6) better accounted for as a symptom of another condition.
\end{abstract}

J. M. Cantor

Campbell Family Mental Health Research Institute, Centre for

Addiction and Mental Health, Toronto, ON, Canada

J. M. Cantor

Department of Psychiatry, University of Toronto, Toronto, ON, Canada

J. M. Cantor $(\bowtie) \cdot$ C. Klein · A. Lykins ·

J. E. Rullo $\cdot$ L. Thaler · B. R. Walling

Sexual Behaviours Clinic, Centre for Addiction and Mental Health,

250 College St., Toronto, ON M5T 1R8, Canada

e-mail: james.cantor@camh.ca
Keywords Hypersexuality · Masturbation - Sex addiction · Sexual compulsivity $\cdot$ Sexual disorders $\cdot$ Typology

\section{Introduction}

Clients have been seeking professional help to control extremely frequent or hyper- sexual urges and behaviors since the 1800s (e.g., von Krafft-Ebing, 1886; Rush, 1812). Every major school of psychotherapeutic thought has been applied in hopes of understanding such clients' reported distress, sometimes with attempts to reduce the urges/behaviors presented (e.g., Quadland, 1985; Salmon, 1995) and sometimes by reinterpreting the clients' complaint as an internalization of arbitrary social norms about sexuality (e.g., Klein, 2003; Levine \& Troiden, 1988) or as an attempt to escape responsibility for their sexual behavior (e.g., Berlin, 2001).

Multiple theoretical models have been asserted in the clinical literature to explain hypersexual behaviors, most frequently the addiction, compulsivity, and impulsivity models (e.g., Barth \& Kinder, 1987; Coleman, 2003; Goodman, 2001). These attempts to identify a single underlying feature common to all cases of hypersexuality have oftentimes been asserted ambitiously: In their introduction to The Sex Addiction Workbook, Sbraga and O'Donohue (2003) claimed "No matter what the sexual problem is, the causes and treatment are the same" (p. 3). Goodman (2001) expressed the idea even more broadly: "All addictive disorders, whatever the types of behavior that characterize them, share an underlying psychobiological process, which I call the addictive process" (p. 207). Despite the numerous comparisons and debates regarding those models (e.g., Barth \& Kinder, 1987; Berlin, 2001; Coleman \& Grant, 2011; Goodman, 2001), no one model has yet met with compelling outcome data (Bancroft, 2008). 
One possible reason for the lackluster evidence behind the existing models of hypersexuality is that they all repeat the same mistake: They presume that one size fits all. That is, rather than provide the clinician with a means for identifying the relevant features of an individual client's situation-and, thereby, a means to identify which interventions to considerthe existing models each suggest a single conceptualization, to be applied no matter what the clinical profile of the actual case.

This assumption of hypersexuality as a unitary phenomenon exists despite that most clinical authors emphasize the diversity of clinical presentations they observe. That diversity, in addition to our own experience with such referrals, suggests a different, if somewhat obvious, idea: There is more than one clinical phenomenon in play, and no single model applies to all clients presenting with or complaining of hypersexuality. This is not to say that all or even any of the existing models are necessarily in error. Rather, what we reject is the (sometimes only implicit) assertion that cases of hypersexuality - no matter how broadly or vaguely defined-all represent the same underlying problem and therefore all merit the same label and approach to treatment. Instead, there appear to be different types of hypersexuality referral, with different types better conceptualized (and treated) in different ways, including conceptualizing some cases as factitious. For emphasis, it is the types of hypersexual referral being described here; some proportion of these cases may not meaningfully be called "hypersexual" at all.

There have been some limited exceptions to the presumption that hypersexuality represents a single phenomenon (see Orford, 1978); at least, there have been authors who, in describing clients complaining of hypersexuality, have enumerated or indicated subtypes (e.g., Bancroft, 2008; Coleman, 1992; Kafka, 2010; Levine, 2010).

As did Levine (2010), the typology presented here divides cases "according to perceived essential similarities" (p. 206). (This is unlike a taxonomy, wherein the categories, or taxa, are established on the basis of distinct etiologies — although the types presented here may ultimately prove to be etiologically distinct from each other, there are few data to support that assertion as yet.) There are, of course, many features that one might deem to be the essential ones. The present typology employs an explicitly treatment-oriented approach. That is, we differentiated types so as to maximize their utility in selecting from among the options for intervention.

Despite continuing debate over conceptual models, authors have been coalescing on broad, yet very similar, suggestions for treatment. It is repeatedly recommended that clinicians employ a multi-faceted or multi-model approach, tailored to individual clients' needs: anti-androgens for their anti-libidinal effects, selective serotonin-reuptake inhibitors (SSRIs) for their anti-compulsive/impulsive effects, cognitive-behavioral techniques for relapse prevention, couples' counseling, motivational interviewing, and, in some cases, psychoeducation about human sexuality and no systematic therapy at all (Coleman, 2003; Kafka, 2007; Kaplan \& Krueger, 2010; Kingston, in press; Kingston \& Firestone, 2008). Absent from the literature, however, is any guidance for matching the widely varying clinical presentations to those potential interventions. That is, although there appears to be some consistency in the recognition of a diversity of presentations and in the family of treatments to consider, the literature does not provide more specific recommendations for which of the many presentations suggest which of the many potential treatments. The present article therefore presents a clinical typology for clients who complain of hypersexuality, using suggested treatments as the basis for classification. (Detailing the contents of the treatments themselves, however, is outside the present scope.)

To illustrate the typology, the following series of case studies was selected from those cases attending the Sexual Behaviours Clinic (SBC) of the Centre for Addiction and Mental Health (Toronto, Canada) — a large, interdisciplinary, mental healthcare facility and teaching hospital of the University of Toronto. By being part of the Canadian public healthcare system, prospective clients experience no out-of-pocket expenses or other financial barriers to clinical services; thus, clients of the SBC may represent a wider demographic range than is available to most private clinics.

The SBC is a tertiary, rather than a primary, care providerit provides clients with specialized clinical (sexological) services that are usually unavailable from general care providers. Clients receive appointments upon referral by a licensed physician, such as a psychiatrist, family practitioner, or walk-in clinic. Thus, although many physicians will provide a referral upon request, an initial screening process can thereby be imposed. The SBC receives referrals and consultation requests pertaining to the full range of sexual phenomena, of which hypersexuality referrals represent a subset. The cases included in this article all were assessed by or under the clinical supervision of the first author.

\section{Types of Hypersexuality Referral}

\section{Paraphilic Hypersexuality}

Approximately a third of the hypersexuality referrals to the SBC exhibit a profile we call Paraphilic Hypersexuality, which has two key features: First, persons of this type report extremely high frequencies of one or more sexual behaviors, sufficient to lead to distress. Such behaviors have included chronic adultery, several hours per day viewing pornography or seeking sexual partners over the Internet, and very frequent solicitation of prostitutes. Second, persons of this type report multiple, but often low-grade or subclinical, paraphilic interests. On initial presentation, the client (or the care provider who referred the 
client) often emphasizes only the frequent behaviors and neglects the paraphilic interests. In our experience, however, clients are quite forthcoming about those interests, once prompted by the clinician.

Roger is a 33-year-old male referred after he was seen in a hospital emergency room, presenting with depression, agitation, and suicidal ideation, following his girlfriend's discovery of his sexual interests. The client reported he was "obsessed with sex" and had a "sex addiction." He indicated that he spends more than half of every day thinking about sex and that he has been "leading two different lives"- one with his girlfriend and one with his other sexual partners. He reported masturbating up to five times per day (two to three, on average), having called chat lines for phone-sex two to three times per week, and not having been faithful to any of his girlfriends since adolescence.

Roger reported that his sexual urges have led him to view pornography on his work computer and to leave work early to meet a partner for a sexual encounter. He indicated he has never been caught for either. He added that he feels low about himself after his episodes of infidelity and volunteered that he uses sex both as a way to regulate negative emotions and to reward himself for accomplishments.

With respect to the type of person to whom he is sexually attracted, Roger said, "I'm embarrassed to say this, but anything with two feet and a heartbeat."He reported no specific sexual preferences with respect to the physical characteristics of his sexual partners (such as breast size, hair color, or ethnicity), endorsing a strong erotic interest in women and some interest in men, but also a substantial erotic attraction to persons who were female in appearance, with fully developed female breasts, but also with a functioning, fully developed penis on the otherwise feminine-appearing body.

With respect to his sexual activity interests, Roger said, "The more adventurous, the better." He reported an interest in having sex in public places, including parks, parking lots, and nightclubs. He indicated that he does not believe that he truly wants to be caught having sex in these public places, but that he likes the thrill that accompanies the risk. He reported that he also has an interest in covertly viewing others having sex. He reported creeping up to the windows of certain hotels where prostitutes are known to take their clients, in order to watch the couples having sex. In one incident, he intended to solicit a specific prostitute he knew, but found that another customer had hired her before he could. So, he instead covertly followed them to watch them having sex.
Roger reported that he similarly enjoyed viewing pornography of persons who were unaware of being recorded and that he had made video recordings of his own sexual encounters, both with and without his partners' knowledge. He reported that he has never publicly distributed these, but that he enjoys masturbating to them. His sexual repertoire also includes erotic asphyxiation, wherein he and his partner choke one another with their hands or arms. He does not engage in erotic selfasphyxiation. The client acknowledged that he enjoys masturbating while wearing women's underwear, but reported no arousal to the thought of himself as woman, noting instead that his arousal is associated with the undergarment itself.

Although Paraphilic Hypersexuals often report that very many stimuli can sexually excite them, some speak rather tentatively in relating their interests, referring to some as historical or transient. Many Paraphilic Hypersexuals also appear to lack the strong, internal directedness that most men report regarding their sexual interest(s). Instead, Paraphilic Hypersexuals will report testing out or going along with a partner's sexual interests, but neither with the enthusiasm expressed by typical paraphilic men (i.e., paraphilic men without hypersexuality) nor with the revulsion that euphilic (i.e., non-paraphilic) (Cantor, 2012) men would express when confronted with the concept. One case reported that he habitually visited websites that provide long lists of paraphilic genres, viewing their contents simply in their alphabetic order, masturbating to all of them, reporting that he found sexual situations in general to be arousing. Unlike typical paraphilic menwho express (and sometimes embellish over a lifetime) rigidly specific interests-Paraphilic Hypersexuals sometimes appear very non-specific in their interests.

Very frequent solicitation of prostitutes is a common (but not universal) component of this type of referral. Because other types of hypersexuality also solicit prostitutes frequently, such solicitation per se does not identify a case as belonging to this type. Interestingly, many Paraphilic Hypersexuals' descriptions of their interactions with prostitutes or erotic dancers include an attraction or desire to become a part of the sex workers' milieu:

Kurt is a 30-year-old male referred for assessment for "addiction to pornography, masturbation, and strip clubs." He reported sexual interests in urophilia, coprophilia, and hebephilia ${ }^{1}$ and having spent more than $\$ 11,000$ hiring lap dancers and strippers to urinate on him or let him penetrate them anally with his finger; however, he reported that the most satisfying activity for him was being able to go out for cigarettes with the

\footnotetext{
${ }^{1}$ Hebephilia refers to the sexual interest in children in early pubescence (Glueck, 1955), with Tanner stage 2-3 anatomy, typically ages 11-14.
} 
strippers after the aforementioned activities: He described its significance as "I've conquered just being a customer."

Some clients have expressed that they feel a sexual charge from, or a draw to, the unseemly environment or illicit nature of street prostitution. Such expressions have also included the desire to prostitute themselves, which often evaporates when the person discovers that the reality fails to measure up to the fantasy. Other cases have reported taking on prostitutes as "projects," and some date prostitutes nearly exclusively.

One remarkable feature of Paraphilic Hypersexuality is that a sizeable number of such persons report gynandromorphophilia, a rarely discussed erotic interest in persons with both male and female anatomy (typically, full breasts and an intact penis), such as possessed by incompletely transitioned male-to-female transsexuals (Blanchard, 1993; Blanchard \& Collins, 1993; Money \& Lamacz, 1984). Although typically describing themselves as heterosexual, Paraphilic Hypersexuals often report seeking out pornography or entertaining sexual fantasies involving "she-males,", and many have had sexual contact with such persons (or with intact biological males), although others have limited themselves to sexual fantasy and pornography. In many cases, the enduring (if low-intensity) erotic interest in she-males or males has led Paraphilic Hypersexuals to confusion about their sexual orientation or gender identity, referring to themselves hesitatingly as "mostly heterosexual" or as bisexual.

There is little evidence to support any method of changing paraphilic interests into euphilic interests. Rather, treatment suggestions include lifestyle integration (for interests that can be expressed alone or with consenting partners) and harm reduction (for those interests that cannot). It is outside the scope of the present article to outline such interventions, but the Internet has permitted persons with even the rarest of sexual interests to form communities for support, for political advocacy, and for social and sexual networking. Because Paraphilic Hypersexuals describe less rigid (or, perhaps, more exploratory) sexual interests than do paraphilic men without hypersexuality, it remains unknown to what extent that the array of interests might be modifiable (unlike paraphilic men without hypersexuality).

It is for the Paraphilic Hypersexuals that medications may be the most relevant. SSRIs have been reported to reduce both libido and impulsivity, but can also delay or entirely prevent ejaculation (e.g., Corona et al., 2009), leading men to seek greater stimulation to trigger orgasm. Endocrinological agents

\footnotetext{
2 There does not exist any universal term to describe persons with this combination of physical traits. Many such persons describe themselves as she-males, express the desire to retain their penis while living socially female lives, and pride themselves on their mixed status; however, there also exist male-to-female transsexuals who abhor their male genitalia and express offense at the term she-male.
}

(anti-androgens) also reduce libido-potentially more effectively than do SSRIs-but have a less tolerable side-effect profile (for a review, see Saleh \& Berlin, 2003). "Chemical castration" with such agents is rarely recommended outside a forensic context.

\section{Avoidant Masturbation}

The next largest subset of hypersexuality referrals received by our clinic is characterized by what appears to be Avoidant Masturbation. The presenting complaint from such individuals, thus far exclusively men, is that they expend inordinate amounts of time viewing pornography and masturbating. Although there does not exist any clear boundary between healthy and pathological amounts of masturbation, the persons in this category report masturbating several hours per day, having been fired from jobs for seeking online pornography or masturbating during work hours, failing classes, and forgoing other major life activities (such as social relationships or hobbies) to spend the time masturbating.

Unlike the Paraphilic Hypersexuals (many of whom also report extreme frequencies of masturbation), persons who engage in Avoidant Masturbation report little, if any, paraphilic interest. Upon interview, they report seeking conventional pornography, often involving women with large breasts, three-way sexual encounters, and conventional sexual role-playing (doctor-nurse, etc.). Although some Avoidant Masturbators report an interest in mild and consensual bondage or discipline, the level of their interest in unconventional activities is far lower than that of the wide-ranging, more frankly paraphilic interests of the Paraphilic Hypersexuals.

Rajeev is a single, 22-year-old male, referred for an assessment of "an Internet pornography addiction." He reported that he spends 4-5 hours daily viewing Internet pornography, but that he is not sure he actually has a problem. He started viewing Internet pornography when he was 14 and currently masturbates $1-3$ times per day. The client has been in two serious relationships and reported that his pornography use remained relatively consistent regardless. He reported that he "cannot look at the same thing more than once" and that seeking new images and videos takes up the majority of the time he spends masturbating. Rajeev also stated that his pornography use sometimes gets in the way of his schoolwork and that he has been 10-15 minutes late to meetings because he was masturbating.

Rajeev stated that when he wants to look at pornography, he must do so, finding it difficult to postpone gratification. He believes his pornography use is a "procrastination tactic" that he uses to avoid doing schoolwork 
or housework. He added he now feels tired of being disappointed in himself and feels that he is "stuck in a rut," with no follow-through for important activities. The client noted repeatedly that he has difficulty delaying gratification in any sense, not only for masturbation but also for buying himself things or engaging in other enjoyable activities. He reported he finds it difficult, in general, to deny himself things that he wants.

Very many of the men who report schoolwork or employment problems brought on by extreme masturbation frequencies acknowledge or even volunteer that they masturbate to avoid a task or chore. Interestingly, the link between masturbation and procrastination has not gone unnoticed by the public: The Urban Dictionary (www.urbandictionary.com) contains an entry for procrasturbation, an amusingly accurate portmanteau of procrastination and masturbation. Many Avoidant Masturbators report feelings of anxiety or dysthymia: Whereas some report using masturbation to soothe such emotions, others report that masturbation instead results in anxiety or depression.

Remarkably, Avoidant Masturbation has not always interfered with the clients' frequency of or satisfaction with their sexual activity within their romantic relationships, at least among our referrals. Some Avoidant Masturbators have reported participating in enjoyable activity with their partners in addition to their masturbatory outlets, whereas others have reported having little interest in sex with their partners in favor of masturbation with pornography.

We refer to "avoidant masturbation" because masturbation appears to be the most common behavior associated with this syndrome; however, other low-investment sexual behaviors can also be used for procrastination or avoidance. Within the gay male community, many continuous hours can also be spent frequenting bathhouses, perusing online hook-up sites, engaging in Cybersex, and engaging in sexual activity with very many partners. That is, although masturbation is not always the actual behavior in such cases, the sexual behavior is nonetheless being employed for avoidance, and the same approach to treatment may prove useful.

When confronted with extreme rates of masturbation, clinicians often apply means to block or prevent the behavior(s), such as with the parental controls on home computers. For Avoidant Masturbation, however, it may be more productive to address the avoidance rather than the masturbation. It is for this type of hypersexuality referral that existing suggestions for motivational interviewing techniques would seem the most applicable (e.g., Del Giudice \& Kutinsky, 2007; Kingston \& Firestone, 2008; Orzack, Voluse, Wolf, \& Hennen, 2006). Similarly, interventions aimed at procrastination itself may also be of use. Many behaviors (especially Internetmediated behaviors) can be used to escape less enjoyable activities, and symptom substitution has been reported by clients.

\section{Chronic Adultery}

Our clinic receives more referrals fitting the Paraphilic Hypersexuality and Avoidant Masturbation profiles, yet the type that seems to be the most widely discussed in the public media is a presentation we call Chronic Adultery. Although some Paraphilic Hypersexuals also have cheated on their spouses, the Chronic Adulterers (almost always, if not always, male) lack significant paraphilic interests and instead report unremarkable use of sex toys, costumes, or mild (mostly symbolic) bondage. Chronic Adulterers are outliers specifically regarding the frequency of cheating on their spouses, but lack the extreme amounts of time spent engaging in or seeking out sexual gratification. Avoidant Masturbation shows the reverse: They expend extreme amounts of time, but do not appear to cheat on their spouses significantly more frequently than population/cultural base rates. The extramarital activities described by Chronic Adulterers have included onetime encounters, on-going sexual relationships, and solicitation of prostitutes. Chronic Adultery would not, however, describe openly non-monogamous or similarly non-traditional relationships wherein no agreement is violated or to situations of a single, on-going or long-term extramarital relationship, despite that it included many episodes of sexual behavior.

Tom is a 47-year-old man, heterosexually married for 15 years, with two children. He was referred by his family physician following his request for assistance with his high libido, infidelity, and "sexual addiction." The client reported that he has cheated on his wife "dozens of times," all with different women, and that he would masturbate two to three times daily.

According to Tom, there was a large discrepancy between the frequency and type of sexual activity he and his wife desired; however, he stated that he loved his wife, finds her sexually attractive, and "If that's where I can get [sex], then that's where I want it." He reported he would like to have sex daily whereas he believes she "could go forever without sex." He reported that he and his wife have sex approximately three times per month. He stated that she has never masturbated, has never viewed sexually explicit materials, and is not comfortable engaging in anything other than sex for reproduction. He reported that his wife had been the victim of sexual abuse, which he believed contributed to her inhibition around sexual activities. Tom stated that he hoped that he and his wife could come to a compromise regarding their frequency of sexual activity, 
but that a compromise may be impossible because of his

"sexual addiction."

As with Tom, a Chronic Adulterer will very often report that his wife does or has suffered from some situation that interferes with her enjoyment of sexual activity. These situations have included: coital pain disorders (i.e., dyspareunia); low, or a dramatically lower, libido; a history of having suffered sexual abuse; and a conservative or religious background.

Typically, only the male client, rather than the couple, presents for assessment; thus, only the perspective of the client (and not his partner) is directly available. Because these cases occur within highly conflicted marital situations, one is naturally wary of the accuracy and completeness of the clients' portion of the story; however, to the extent that the wives' perspectives have become available (such as by the couple subsequently attending the clinic together for marital/ relationship counseling), the wives' histories and levels of sexual interest have matched their husbands' descriptions of them. (Relatedly, it has also been our experience that the clients can be more forthcoming with the therapist than with their spouses, such as by revealing more violations of the marriage to the therapist than to their wives.)

The mainstream media regularly display celebrities who profess "sexual addiction" as the explanation for their adultery, suggesting an obvious point: There exist men who may seek treatment, not to attempt to change their behaviors, but for the secondary gain of seeming to make such attempts in the eyes of the public or of their spouses and families. Although such cases undoubtedly exist, the Chronic Adulterers attending our clinic appear to do so in the absence of such a context. These have included cases who, for example, were referred during the height of marital discord, but by the time of the appointment, had separated and decided on divorce-yet with the husband nonetheless attending the appointment, on his own, expressing the desire to understand his own behavior and not to destroy any potential for a successful (monogamous) relationship in the future with someone else.

Although it is rarely made explicit, both public and professional discussions of chronic adultery frequently devolve into frankly judgmental discussions about ethical/moral implications of the adultery and about sympathy for the plight of the wives, with generalizations made from a single (often celebrity) example to all cases of chronic adultery. In practice, however, cases of Chronic Adultery have presented to our clinic at every level of seeming blameworthiness: We have encountered husbands simply unwilling to forgo extramarital affairs and husbands for whom the adultery compensates, or appears to be aimed at compensating, for discrepant libidos between the partners. Whereas the behaviors in Paraphilic Hypersexuality and Avoidant Masturbation are often reported to cause marital distress, the behaviors in Chronic Adultery often appear to result from pre-existing marital distress.
It is this type of hypersexuality referral for which couples' therapy is indicated. Indeed, many aspects of the issues addressed in therapy often appear unassailable without the participation of the partner in therapy. Unfortunately, this type of referral has nearly always attended individually, with a charge from the wife to fix his problem (e.g., his addiction or hypersexuality). We have not found interventions aimed solely at the husband to be productive. Despite the wide variety of marital situations and marital difficulties, what appears to be common across these cases is that one partner (thus far, in our experience, the husband) employed a problematic strategy to address the couple's problematic situation. Discrepant sex drive is very familiar to relationship therapists. Among Chronic Adulterers, the atypically high and atypically low levels of sex drive often predate the relationship, although the heightened sexuality early in relationships, could plausibly delay the salience of the discrepancy to each partner. Instead of addressing the discrepant sex drives directly, however, the Chronic Adulterers have expressed their high sex drives outside the relationship, on a long-term basis.

To the extent that the perspectives of the wives of Chronic Adulterers have become available directly, they have been remarkably ambivalent. As noted already, the women in these relationships typically report (or are reported to have) a history or long-standing condition interfering with their desire to engage in sex. A possibility that is very difficult-but nonetheless worthwhile-to explore is the extent to which the wives may experience relief from the pressure to satisfy the sexual needs of their partner, once he has begun to satisfy those desires outside the relationship. Although the common insistence from the wife is that the husband attend therapy in order to fix his problem, that demand also serves to distract from or excuse unaddressed issues on the part of the wives. Unfortunately, in practice, the husbands' history of deception serves or is used to block discussion of any potential contribution on the part of the wife to the context. Such situations require great caution in treatment, as the distinction can easily be mistaken for victim-blaming.

\section{Sexual Guilt}

In the three aforementioned situations-Paraphilic Hypersexuality, Avoidant Masturbation, and Chronic Adulteryclients reported distress related to sexual behavior(s) they expressed with extreme frequency. Other clients similarly present with self-labels of hypersexuality (etc.) and similarly report great distress (often sufficient to have warranted previous diagnoses of depression), but lack any overt, behavioral extremes. The reported frequencies of sexual behaviorsmasturbation, coitus, adultery, pornography use, etc.-are well within peer group norms (e.g., Laumann, Gagnon, Michael, \& Michaels, 1994). Indeed, some cases report 
unusually low rates of some behaviors, including a man who never had sexual intercourse with his wife of 8 years (or anyone else) and complete abstinence from masturbation. These cases typically report having been raised in highly conservative (usually religious) environments; however, some cases have willfully adopted moralistic standards during adulthood, sometimes exceeding the dictates of their religious affiliations. We refer to such cases as Sexual Guilt.

Kelly is a 40-year-old female, heterosexually married for nine years, with prior diagnoses of Obsessive-Compulsive Disorder and chronic fatigue syndrome. She was referred by her counselor for concerns about "sexual addiction." The client reported that she thinks about sex frequently and that, if she had the energy, she would like to have sex on a daily basis. She reported she masturbates with a vibrator approximately twice per week and only when her husband is not at home, because she is concerned he would feel hurt if he knew she masturbated and experienced orgasms with the vibrator, but not during intercourse with him.

Kelly reported she experiences intrusive thoughts of having intercourse with "whoever is on my mind," noting that she will have thoughts of passionately kissing and having sex with men that she sees throughout her day. She reported that she feels guilty about these thoughts and that she hates them because they involve men other than her husband. The client reported that she has been faithful to her husband, although she has been tempted to cheat. Kelly reported that she began masturbating approximately five years ago, when she first got her vibrator. Kelly had difficulty discussing her practice of masturbation, indicating that she finds "the m-word" dirty and feels guilty about her use of the vibrator.

A substantial proportion of cases of Sexual Guilt have previously presented to other clinicians and carry current or past diagnoses of Obsessive-Compulsive Disorder, Generalized Anxiety Disorder, Social Anxiety, or a mood disorder.

Rather than being predominantly or entirely male, both men and women have presented to our clinic complaining of hypersexuality, but describing Sexual Guilt instead. Most such cases express their anxiety broadly, in terms of all sexual urges or interests; however, we also receive cases who express anxiety with regard to only a subset of the stimuli they find sexually arousing. Such cases include persons who chastise themselves for sexual fantasies that are stigmatized, but nonetheless conventional, such as fantasies about an acquaintance or other non-marital partner. Relatedly, this type of case includes androphilic men who reject or resist their sexual orientation and seek treatment to control what they call their addiction/compulsion/impulses to have sex with men.
(Although the same principle would apply to lesbians, no such case has come to our clinical attention.) Sexual Guilt would also describe the analogous situation of persons with uncomplicated paraphilias (i.e., paraphilias without hypersexuality), such as erotic cross-dressing or sexual masochism, similarly rejecting their predominant sexual interests.

The most indicated interventions for Sexual Guilt are psychoeducation and permission-giving. In practice, however, the clients' inaccurate beliefs about sexuality (and peer norms) are often attached to multiple other aspects of their belief systems. Although this is sometimes an explicitly religious system (or is merely attributed by the client to his or her religious system), it has also included other deeply held ideologies, such as the roles of men and women or new age beliefs about the benefits of abstinence from any of several pleasurable activities.

\section{The Designated Patient}

A sizeable number of referrals are instigated not by the client but by the client's romantic partner. In some instances, such instigation follows from the partner's discovery of the client's infidelity or paraphilic behavior, but in other instances the partner's demands reflect highly restrictive sexual beliefs, such as a zero tolerance for masturbation, pornography, or non-procreative sex. We commonly refer to this latter presentation as the Designated Patient.

Gerry is a 51-year-old father of two children, currently residing with his wife. He was referred by his family physician, following concerns expressed by Gerry's wife regarding his use of pornography. He noted he views pornography in the form of magazines or videos, every couple of years, for up to approximately an hour per week. This has reportedly resulted in marital discord: Gerry indicated that his wife has always expressed a strong opposition to the use of any pornography, telling him he "should have no need or no use for it because I have her." At his wife's request, he disposed of all his pornography when they first began dating and promised her that he would not view pornography again; however, Gerry reported that he has broken this promise numerous times over the course of their marriage, which has led to significant distrust. Gerry reported that he no longer uses the Internet, at his wife's request, as she believes he would use the Internet to view pornography.

Despite that these clients are called sex addicts (etc.) by themselves or by some of their healthcare providers, our experience with this subgroup is that they lack any of the behavioral extremes with which the other types of case present. Numbers of sexual partners (lifetime or current), frequency of masturbation, duration of masturbation, and frequency of 
intercourse are generally unremarkable (cf. Laumann et al., 1994). Indeed, their sexual outlets often appear low relative to the clients' age, sex, and cultural background - and can even suggest that the client possesses an exceptional ability to control his sexual urges, never mind an inability to do so.

Typically, only the client (and not the client's partner) attends for the assessment. Indeed, the client often volunteers that the partner made explicit the belief that the problem is specifically the client's problem to solve. This suggests the obvious possibility that the client may be exaggerating the partner's zero tolerance; however, to the extent that the partners have subsequently attended for couples' therapy and provided their own account, they have confirmed that the expectation was indeed zero tolerance for masturbation or pornography use.

In Designated Patient cases, we have found several interventions to be fruitful: (1) expansion of the case to include the partner, (2) psychoeducation regarding healthy masturbation and pornography use, and (3) communication and assertiveness training. In the abstract, there is, of course, no dividing line between reasonable and unreasonable demands of a partner, and there will no doubt be debate regarding whether a given restriction is a reasonable demand to make of one's partner or whether mental health professionals should have any say in what a reasonable demand is. Typically, sex-positive clinicians quickly identify the partners' demands as overly or unnecessarily restrictive. On the other hand, the clients are aware of and have (usually explicitly) agreed to those restrictions. Thus, the clinician can be put in the role of taking a side: Is the therapeutic goal to address one partner's restrictions or the other partner's failure to maintain the agreed-upon behaviors? In practice, it can be helpful first to educate the couple regarding the healthy nature of masturbation (etc.), to help the couple to explore or re-negotiate their boundaries, and to help the husband to confront and discuss rather than avoid the problem.

\section{Better Accounted for as a Symptom of Another Condition}

There exist several non-sexual diagnoses that nonetheless include hypersexuality as one of its symptoms or sequelae. These include certain personality disorders, hypomania, and developmental delay. Disinhibiting brain injuries and neurological disease have also been reported to result in hypersexual behavior (Mendez \& Shapira, 2013). There have also been reports in the literature of hypersexual behaviors following the administration of certain psychotropic medications. The existence of these phenomena is a reminder of the need for broad history-taking. The most common syndrome for which hypersexuality has presented to our clinic as a single aspect is personality disorder, especially Borderline Personality Disorder.
Jacob is a 39-year-old, openly gay man reporting a history of depression, multiple suicide attempts, and embezzlement from employers to support what the client called his addictions to sex and to shopping. Jacob reported that, since age 14, he engaged in anonymous sexual encounters with men, generally twice weekly to daily, in parks, public washrooms, adult movie theatres, and bathhouses. When asked to estimate his number of sexual partners, he said, "I have no clue. I'm horrified to think about it. To think about it would emotionally scar me." He subsequently estimated 500-900 sexual partners. Since acquiring a computer 14 years ago, he has spent 3-8 hrs/day online (including while at work) viewing male-male pornography and chatting to arrange sexual encounters. The client similarly reported purchasing, selling, and repurchasing thousands of compact discs, spending entire days perusing music online or at local music stores, and shopping after satisfying sexual encounters as a reward to himself.

Jacob admitted embezzling money from his employers to pay his entrance fees into bathhouses, purchase pornographic movies, or hire a taxi ride to meet someone for sex. His embezzlement led to his termination from three separate employers. He is on a leave of absence from his current employment, which his employer suggested as a result of his most recent suicide attempt.

Jacob has been in a cohabitating relationship with his partner for over 10 years. They have an ostensibly monogamous relationship, but Jacob reported his partner to be unaware of the extramarital encounters and described their relationship as "rocky and stressed." They have had no sexual contact with each other for the past five months, the client reporting he feels too guilty about his affairs.

He reported he has "blocked out" most of his memories of his childhood, but that he believes he was "gang raped" by four classmates while in high school. He reported that the details of the incident were "fuzzy" and that it was never reported to authorities. He indicated struggling in school classes when his "relationship with the teacher did not suit [him]." He explained that he was once expected to earn good grades in a particular class, and as a result he purposefully failed the course. He attended some college, but discontinued his education because he wanted to "party and socialize."

Jacob's first suicide attempt was in his teens, secondary to distress about his sexual orientation and being the victim of bullying. His most recent suicide attempt was by overdose of pain-killers, secondary to distress over his sexual addiction. He has participated in psychotherapy previously, terminating treatment after 3-4 sessions, 
saying "I didn't want to talk about the sex stuff." Currently, he sleeps 16-18 hours per day and binge eats (fasting for 3-4 days, then eating large quantities in one sitting). He denied global anhedonia, reporting that he continues to enjoy listening to music, watching television, and reading books.

Consistent with the literature on Borderline Personality Disorder, clients attending our clinic with this profile have very commonly been women and gay men. Referrals of this type sometimes report extremely high masturbation rates, resembling Avoidant Masturbation, or very many instances of adultery, resembling Chronic Adultery. (We have not observed any remarkable frequency of paraphilic interests or paraphilic behavior.) The primary distinction between personality disorders and the other types of hypersexuality referral is in the presence of the other symptoms of the personality disorder, rather than in any obvious difference in the sexual behaviors themselves.

Many, or most, of the other disorders that include hypersexuality with any sizeable frequency are disorders associated with disinhibition. That is, in such cases, the extremely frequent sexual behavior is one among multiple extremely frequent behaviors. We have not yet encountered a referral for which a neurological or other disinhibiting disorder was associated with Chronic Adultery, but have encountered several that showed extremely frequent masturbation or frankly bizarre behaviors that could resemble paraphilias. In the absence of information about a referral's premorbid sexuality, however, the diagnosis can remain unknown.

The personality and other disorders that have hypersexuality as a symptom are included in this one section because, thus far, they appear to be best addressed in the same way: according to the overarching disorder rather than to the hypersexual symptom(s). It is beyond the scope of this article to review the treatment literatures for each; however, in many referrals to our clinic-especially from clinics specialized for people with other disorders - there has seemed to be an avoidance among professionals to integrate the clients' sexual behaviors into his or her clinical profile. That is, out-of-control sex is sometimes automatically viewed as something distinct from other out-of-control behaviors and in need of special attention. In practice, it has been useful to establish a consultative role with clinicians already addressing the overarching issue.

\section{Discussion}

Regardless of whether the types described here ultimately emerge as genuine taxa (that is, regardless of whether the differing apparent features are the result of having distinct etiologies), the present formulation may make two very pragmatic contributions: One is the overarching thesis that the diversity of clients presenting with or complaining of hypersexuality may represent entirely unrelated phenomena. That is, it may be an error to presume a commonality across these types of referral merely because they all pertain to sex and its suppression. The desire to suppress a sexual urge or behavior may be a symptom of any of several problems in the same way that a headache may be a symptom of any of several problems (including being factitious). Second, the present analysis may provide clinicians with guidance as to which potential interventions to consider, given the wide diversity of clinical presentations and multiplicity of interventions mentioned in the literature. To repeat a prior point, there are multiple valid ways in which one may divide this population into types, and the present treatment-oriented approach is only one of them.

This particular typology suggests to clinicians to include in interviews certain questions that can otherwise easily be overlooked. (Because it is necessary to consider these features when employing the present typology, these features become much more central to clinical conceptualization.) The first among these is the presence of paraphilic interests, including a history of sexual fantasies or behaviors involving transgendered persons (specifically, persons who appear feminine but have a penis). Because clients often lack the vocabulary to describe their sexual interests, it can be helpful to canvas and list the pornographic websites they enjoy. Also central to applying this typology is to query behaviors that are not themselves sexual but can suggest which type best fits. Such questions include information about non-sexual forms of avoidance or procrastination (which would suggest that the problematic sexual behavior is one of multiple maladaptive avoidance strategies) and non-sexual symptoms of personality disorders (also embedding the problematic sexual behavior as a single feature of a more general problem). Table 1 provides some of the questions we have found useful in eliciting information helpful to employing the present typology. Finally, because the present typology also includes distress that clients attribute to sexuality (but is not actually due to that sexuality), the present typology requires consideration of characteristics of the partner (such as pre-existing inhibitors of healthy sex).

Although some authors fail to distinguish between typologies and taxonomies, the present groupings represent a typology: The categories are not as yet shown to have distinct etiologies, and they are not necessarily mutually exclusive. That is, having features of one type does not obviate having features of the other types, nor does the absence of one (or more) features of one type necessarily indicate that that type is irrelevant. Indeed, clients who seem to fit more than one type may benefit from the interventions suggested by each of those types.

The notion of there being multiple types also carries an implication for interpreting data from samples of persons who refer themselves for hypersexuality. That is, what would emerge when a researcher gathers and analyzes data from 
Table 1 Suggested items to include for assessment of hypersexuality referrals

Interview questions

1. How much of your concern is about how much sex, and how much is about what kind of sex or kind of people you want sex with?

2. Some people who hire prostitutes are after simple, physical sex, but other people want other kinds of relationships with the prostitutes. What's your ideal?

3. Which porn websites do you go to?

4. Masturbating for several hours per day is certainly higher than average. What would you be doing with that time if not masturbating?

5 . How do you deal with stress? What's worked for you? What hasn't?

6. Why did you get married? How has it matched up with what you expected?

7. What would your partner's sex life be like if you had never met?

8 . How does religion influence your life besides sex?

9. How much of the problem is about posing harm to yourself (or others), and how much is about what it means about you as a person?

10. Although finding sex is the part that attracts our attention, for many people the problem is more about finding relationships. How do these go together for you?

hypersexual individuals, but inadvertently capturing several different types within that single sample? The data would show a broad range of low-grade associations. That is, instead of having one subtype with paraphilic interests and one subtype with avoidance characteristics (etc.), one would instead obtain a sample only some of which shows paraphilias, some of which shows avoidance, etc. Unless specific precautions were taken, such samples would also include persons with inhibited sexuality and persons with (perhaps undiagnosed) personality disorders, etc. If it is the case that hypersexuality referrals are composed of multiple types, then heterogeneous samples of such individuals would show a very wide range of atypical characteristics, each with depressed effect sizes. Remarkably, this appears to describe a sizeable portion of the published literature on hypersexuality: A researcher hypothesizes a deficit or excess in any of many characteristics, then (lacking any explicit method of isolating comparatively homogeneous subgroups or eliminating factitious cases, etc.) obtains a mixed sample that reveals some amount of the hypothesized feature and declares that feature to be pertinent to the entire phenomenon of hypersexuality rather than only to a certain subtype.

Acknowledgments We are grateful to Marta Meana, Neil W. Pilkington, and Katherine S. Sutton for their comments on earlier versions of this article. This research was supported by Canadian Institutes of Health Research grant 89719 to James M. Cantor.

\section{References}

Bancroft, J. (2008). Sexual behavior that is "out of control": A theoretical conceptual approach. Psychiatric Clinics of North America, 31, 593-601.
Barth, R. J., \& Kinder, B. N. (1987). The mislabeling of sexual impulsivity. Journal of Sex and Marital Therapy, 13, 15-23.

Berlin, F. (2001). The Vanderbilt Symposium-In my opinion. Sexual Addiction \& Compulsivity, 8, 187-189.

Blanchard, R. (1993). The she-male phenomenon and the concept of partial autogynephilia. Journal of Sex and Marital Therapy, 19, 69-76.

Blanchard, R., \& Collins, P. I. (1993). Men with sexual interest in transvestites, transsexuals, and she-males. Journal of Nervous and Mental Disease, 181, 570-575.

Cantor, J. M. (2012). Is homosexuality a paraphilia? The evidence for and against. Archives of Sexual Behavior, 41, 237-247.

Coleman, E. (1992). Is your patient suffering from compulsive sexual behavior? Psychiatric Annals, 22, 320-325.

Coleman, E. (2003). Compulsive sexual behavior: What to call it, how to treat it? SIECUS Report, 31(5), 12-16.

Coleman, E., \& Grant, J. (2011, April). Controversies in diagnostic nomenclature: Hypersexuality as sexual compulsion versus sexual addiction. Debate presented at the meeting of the Society for Sex Therapy and Research, Palm Beach, FL.

Corona, G., Ricca, V., Bandini, E., Mannucci, E., Lotti, F., Boddi, V., et al. (2009). Selective serotonin reuptake inhibitor-induced sexual dysfunction. Journal of Sexual Medicine, 6, 1259-1269.

Del Giudice, M. J., \& Kutinsky, J. (2007). Applying motivational interviewing to the treatment of sexual compulsivity and addiction. Sexual Addiction and Compulsivity, 14, 303-319.

Glueck, B. C., Jr. (1955). Final report: Research project for the study and treatment of persons convicted of crimes involving sexual aberrations. June 1952 to June 1955. New York: New York State Department of Mental Hygiene.

Goodman, A. (2001). What's in a name? Terminology for designating a syndrome of driven sexual behavior. Sexual Addiction and Compulsivity, 8, 191-213.

Kafka, M. P. (2007). Paraphilia related disorders: The evaluation and treatment of nonparaphilic hypersexuality. In S. R. Leiblum (Ed.), Principles and practice of sex therapy (4th ed., pp. 442-476). New York: Guilford.

Kafka, M. P. (2010). Hypersexual disorder: A proposed diagnosis for DSM-V. Archives of Sexual Behavior, 39, 377-400.

Kaplan, M. S., \& Krueger, R. B. (2010). Diagnosis, assessment, and treatment of hypersexuality. Journal of Sex Research, 47, 181-198.

Kingston, D. A. (in press). Hypersexual disorder: Conceptualization, assessment, and intervention. In A. Phenix \& H. Hoberman (Eds.), Diagnosis, risk assessment, and management of sexual offenders. New York: Springer.

Kingston, D., \& Firestone, P. (2008). Problematic hypersexuality: A review of conceptualization and diagnosis. Sexual Addiction and Compulsivity, 15, 284-310.

Klein, M. (2003). Sex addiction: A dangerous clinical concept. SIECUS Report, 31(5), 8-11.

Laumann, E. O., Gagnon, J. H., Michael, R. T., \& Michaels, S. (1994). The social organization of sexuality: Sexual practices in the United States. Chicago: University of Chicago Press.

Levine, S. B. (2010). What is sexual addiction? Journal of Sex and Marital Therapy, 36, 261-275.

Levine, M. P., \& Troiden, R. R. (1988). The myth of sexual compulsivity. Journal of Sex Research, 25, 347-363.

Mendez, M. F., \& Shapira, J. S. (2013). Hypersexual behavior in frontotemporal dementia: A comparison with early-onset Alzheimer's Disease. Archives of Sexual Behavior. doi:10.1007/s10508012-0042-4.

Money, J., \& Lamacz, M. (1984). Gynemimesis and gynemimetophilia: Individual and cross-cultural manifestations of a gender-coping strategy hitherto unnamed. Comprehensive Psychiatry, 25, 392403.

Orford, J. (1978). Hypersexuality: Implications for a theory of dependence. British Journal of Addiction, 73, 299-310. 
Orzack, M. H., Voluse, A. C., Wolf, D., \& Hennen, J. (2006). An ongoing study of group treatment for men involved in problematic Internetenabled sexual behavior. CyberPsychology \& Behavior, 9, 348-360.

Quadland, M. C. (1985). Compulsive sexual behavior: Definition of a problem and an approach to treatment. Journal of Sex and Marital Therapy, 11, 121-132.

Rush, B. (1812). Medical inquiries and observations, upon the diseases of the mind. Philadelphia: Kimber \& Richardson.

Saleh, F. M., \& Berlin, F. S. (2003). Sex hormones, neurotransmitters, and psychopharmacological treatments in men with paraphilic disorders. Journal of Child Sexual Abuse, 12, 233-253.
Salmon, R. F. (1995). Therapist's guide to 12-step meetings for sexual dependencies. Sexual Compulsivity \& Addiction, 2, 193-213.

Sbraga, T. P., \& O'Donohue, W. T. (2003). The sex addiction workbook: Proven strategies to help you regain control of your life. Oakland, CA: New Harbinger.

von Krafft-Ebing, R. (1886). Psychopathia sexualis with special reference to the antipathic sexual instinct: A medico-forensic study (12th ed.) (F. J. Rebman, Trans.). New York: Putnam. 